\section{Epidemiology of childhood IDDM in Athens: trends in incidence for the years 1989-1995}

\section{Dear Sir,}

Previous national data on the epidemiology of insulin-dependent diabetes mellitus (IDDM) in Greece have demonstrated a remarkable difference in the IDDM risk between urban and rural populations [1-4]. Thus, the Greek contribution to the EURODIAB ACE Concerted Action study showed incidence of IDDM in the first 2 years (1989-1990) to be about 9 per 100000 children aged $0-14$ years in the metropolitan Athens area and 4.6 per 100000 in the mostly rural population of Northern Greece (5 districts of Macedonia) [1-4]. Furthermore, a previous survey of admissions to the "P. \& A. Kyriakou" Athens Children's Hospital of newly diagnosed patients with IDDM showed a $10 \%$ annual increase when comparing admissions during the years 1972-1975 and 1982-1985 [5]. Therefore, a prospective study of the prevalence of IDDM in the Athens metropolitan area was considered appropriate in order to define possible trends and variation.

All paediatric and paediatric endocrine departments of the hospitals of the metropolitan Athens area, as well as their outpatient diabetology units participated in the study by reporting all new cases of IDDM with the first insulin injection given before the age of 15 years and during the period 1989 through 1995. Cases were included if resident permanently in the metropolitan Athens region at least for 1 year prior to onset of the symptoms. A 10-day minimum continuous administration of insulin was considered to be a prerequisite for the diagnosis of IDDM. Ascertainment was validated using inquiries to practicing diabetologists and parents' associations as one combined secondary and independent ascertainment source.

Incidence rates, expressed as number of new cases per 100000 person-years at risk were estimated, using census data from 1991 with extrapolations for the surrounding years, as obtained from the National Statistics Service of Greece. Incidence rates were calculated for age intervals $(0-4,5-9$ and 10-14 years) and for each sex. Standardized rates were calculated, assuming a standard population with age and sex groups

Corresponding author: C.S.Bartsocas, M.D., University of Athens, P.O. Box 17177, GR-10024 Athens, Greece of equal sizes. Chi-square tests were used to investigate heterogeneity by calendar year and for comparison of male to female differences. Validation of ascertainment was based on the capture-recapture method [6].

In total, 388 cases ( 224 boys and 164 girls) were ascertained during the registration period of 7 years. Of these, 375 cases were ascertained independently by the two sources, two cases were ascertained by the primary, but not the secondary source, whereas 11 cases were ascertained exclusively by the secondary source. This yields an overall ascertainment probability of $99.98 \%$ (95 \% confidence limits: $99.86-100.00 \%$ ), with no differences between the individual calendar years.

Table 1 shows the annual sex-specific standardized incidence rates for each calendar year and for the whole study period combined. Overall, the ratio of standardized incidence rates for boys and girls was statistically significantly increased at $1.28(p=0.010)$. The standardized incidence rates (boys and girls combined) was for the whole study period 9.7 per 100000 , ranging from 7.8 in 1994 to 12.0 in 1992 . Overall, there was no statistical evidence of heterogeneity by calendar year (chi-square, stratified for age and sex: $7.358($ d.f. $=6)$, $p=0.289$ ). None of the individual calendar years deviated statistically significantly from homogeneity.

Trends in the age- and sex-specific incidence rates are shown in Figure 1. None of the three age groups showed evidence of heterogeneity by calendar year when stratified for sex (chi-square $(d . f .=6)$ for $0-4$ years: $8.891, p=0.180$; 59 years: $3.061, p=0.801 ; 10-14$ years: $11.470, p=0.075)$.

The aim of this study was to determine the incidence of IDDM in the metropolitan Athens area, covering about $35 \%$ of the total Greek population. The study population is urbanized, with little migration. By studying the Athenians it was hoped to establish the possible incidence trends existing in a stable genetically homogeneous population. Any identifiable trend changes may be helpful in the study of possible aetiological factors, thereby leading to the elucidation of possible environmental causes of IDDM.

The EURODIAB ACE incidence study was initiated in 1988 , i. e. $10-15$ years after a remarkable increase in the incidence of IDDM in Greece [5]. Our data, however, confirm a relatively stable incidence at about 9-10 per 100000 children annually. This is almost twice the incidence of IDDM in the countryside (mixed urban and rural) population of Macedonia, Northern Greece [3]. It is also higher than the nationwide incidence survey performed in 1992 [4]. 
Table 1. Number of cases and standardized incidence rates by calendar year

\begin{tabular}{|c|c|c|c|c|c|c|c|c|c|}
\hline \multirow[t]{2}{*}{ Year } & \multicolumn{2}{|c|}{ Number of cases } & \multicolumn{2}{|c|}{ Population size } & \multicolumn{3}{|c|}{ Standardized $^{\mathrm{a}}$ rate per 100000} & \multicolumn{2}{|c|}{ Test of sex difference ${ }^{b}$} \\
\hline & Boys & Girls & Boys & Girls & Boys & Girls & All & $\begin{array}{l}\text { Chi square } \\
\text { (1 d.f.) }\end{array}$ & $\mathrm{p}$ value \\
\hline 1990 & 34 & 28 & 335793 & 323032 & $9.8 \pm 1.7$ & $8.3 \pm 1.6$ & $9.0 \pm 1.2$ & 0.42 & 0.515 \\
\hline 1991 & 36 & 25 & 286857 & 271805 & $12.3 \pm 2.1$ & $8.9 \pm 1.8$ & $10.6 \pm 1.4$ & 1.43 & 0.232 \\
\hline 1992 & 31 & 35 & 268799 & 254471 & $10.4 \pm 2.1$ & $13.6 \pm 2.3$ & $12.0 \pm 1.6$ & 0.51 & 0.476 \\
\hline 1993 & 30 & 18 & 258708 & 244850 & $11.5 \pm 2.1$ & $7.3 \pm 1.7$ & $9.4 \pm 1.4$ & 2.38 & 0.123 \\
\hline Total & 224 & 164 & & & $10.9 \pm 0.8$ & $8.5 \pm 0.7$ & $9.7 \pm 0.5$ & 6.667 & 0.010 \\
\hline
\end{tabular}

Data are mean \pm 1 SEM

a The standard population assumes equal sizes of age groups $0-4,5-9$ and 10-14 years for boys and girls

b Stratified for age groups 0-4, 5-9, 10-14 years
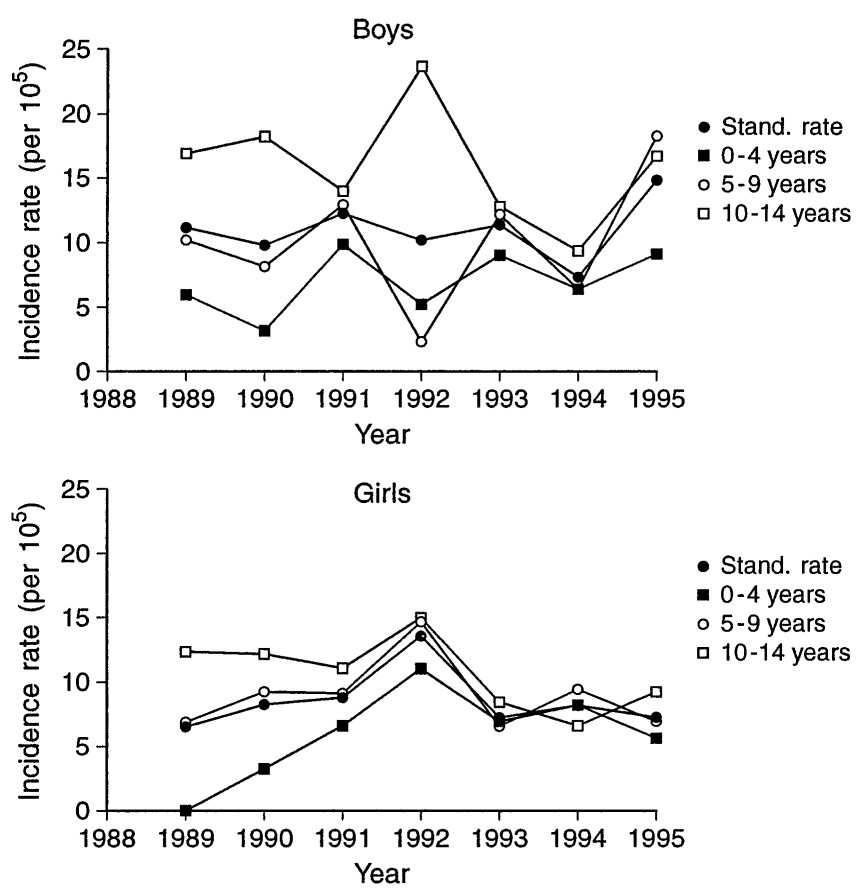

Fig. 1. Trends in incidence rates

It is difficult to speculate on the reasons for this extreme variation between genetically similar groups. Possibly, living in a large city may cause early exposure to environmental factors such as viral agents, pollution and even stress.

The increased ratio in incidence between boys and girls confirms observations in most countries [1]. It remains to be explained whether this is a result of parental imprinting or it is caused by other mechanisms.

The present data show no differences in the incidence of IDDM during an observation period of 7 years, in contrast to previous retrospective studies, which indicated a $10 \%$ annual rise [5].

The fact that increased incidence was not observed in this study could indicate either that the present sample is more representative of the population studied or, most probably, that the incidence of IDDM is levelling off in Athens, as has been thought previously [4].

Greece is a small country, with about 10.5 million inhabitants. Nonetheless, this country represents several opportuni- ties for descriptive epidemiological and aetiological studies of IDDM. Genetic homogeneity and low migration levels over the recent 30-50 years are just a few examples of such opportunities. It is obvious that further studies are needed in order to elucidate explanations underlying the age trends, sex difference and geographical variability in the presentation of IDDM.

Acknowledgements. This study represents the Greek contribution to the EURODIAB ACE Concerted Action which is sponsored in terms of coordination by the EU Medical Research Programme (Contract no. BMH1-CT92-0043).

Yours sincerely,

C.S.Bartsocas, C.Dacou-Voutetakis, D.Damianaki, C.H.Karayanni, C. Kassiou, A. Qadreh, C.H. Theodoridis, H. Tsoka, A. Green, for the Eurodiab ACE G1 Group

\section{References}

1. Green A, Gale EAM, Patterson CC for the EURODIAB ACE GROUP (1992) Incidence of childhood-onset insulindependent diabetes mellitus. The EURODIAB ACE study. Lancet 1: 905-909

2. Bartsocas CS, Dacou-Voutetakis C, Damianaki D et al. (1991) Incidence of IDDM in the Childhood Population of Greater Athens, Greece. Materia Medica Greca 19: 249251 (in Greek)

3. Papazoglou N, Manes C, Soulis C et al. (1993) Incidence of new IDDM cases in children of Northern Greece. Hell Diabet Chron 6: 31-36 (in Greek)

4. Dacou-Voutetakis C, Karavanaki K, Tsoka-Gennatas H (1995) The Hellenic Epidemiology Study Group. National Data on the Epidemiology of IDDM in Greece. Diabetes Care 18: 552-554

5. Bartsocas CS, Karayanni C, Stamoyannou L, Ktenas E (1988) Incidence and differences in urban-rural seasonal variation of type I diabetes in Greece. Diab Res Clin Pract [Suppl I), Elsevier Publishers, Amsterdam

6. Bishop YMM, Fienberg SE, Holland PW (1974) Discrete multivariate analysis: theory and practice. MIT Press, Cambridge, Massachusetts

7. Bingley PJ, Gale EAM (1989) Incidence of insulin-dependent diabetes in England: a study in the Oxford region, 1985-6. BMJ 298: 558-560 